\title{
Comparison of Neural Network Models in the Estimation of the Performance of Solar Still Under Jordanian Climate
}

\author{
M. A. Hamdan, R. A. Haj Khalil, and E. A. M. Abdelhafez
}

\begin{abstract}
Three Artificial Neural Network models (Feedforward, Elman, and Nonlinear Autoregressive Exogenous (NARX) networks) were used to find the performance of triple solar still operating under Jordanian climate. Previously obtained experimental data was used to train the neural network. time, Hourly variation of cover glass temperature $\left(T_{g}\right)$, water temperature in the upper basin $\left(T_{w 1}\right)$, water temperature in the middle basin $\left(T_{w 2}\right)$ and water temperature in the lower basin of the triple basin still $\left(T_{w 3}\right)$, Distillate volume, ambient temperature $\left(T_{a}\right)$, plate temperature $\left(T_{P}\right)$ and hourly solar intensity $\left(I_{s}\right)$ were used in the input layer of the network. The thermal efficiency $(\eta)$ of a triple basin solar still was in the output layer. The obtained results were verified against previously obtained experimental data. It was found that Artificial Neural Network technique may be used to estimate the efficiency of the triple solar still with excellent accuracy with the coefficient of determination of Elman, feedforward and NARX models were found to be 0.9036 , 0.99838 and 0.99863 , respectively. The obtained results showed that feedforward model had the best ability to estimate the required performance, while NARX and Elman network had the lowest ability to estimate it.
\end{abstract}

Index Terms-Artificial neural network, elman, NARX, feedforward, solar still.

\section{INTRODUCTION}

Currently, Jordan has a substantial dependence on foreign energy sources with $96 \%$ of its needs served by imports of oil products, natural gas and electricity. Due to population growth and economic prosperity and the growing demand for energy in Jordan, the Kingdom has focused its efforts to meet portion of the energy demand through the development of alternative sources of energy and renewable resources such as wind, solar, and geothermal. In addition and to cut down energy saving programs were launched which concentrate on energy audit through capacity building and public awareness. Jordan has the potential to generate its own energy through solar energy.

At least one third of the population in developing countries has no access to safe drinking water. The lack of adequate water supply and sanitation facilities causes a serious health hazard and exposes many to the risk of water-borne diseases. As a result of that, researchers focused their work on oceans and seas in order to obtain fresh potable water by distillation

Manuscript received October 22, 2012; revised January 11, 2013.

M. A. Hamdan and E. Abdelhafez are with the engineering faculty, Al Zaytoonah University of Jordan, Amman, Jordan (e-mail: engineering @zuj.edu.jo, eman.abdelhafez@zuj.edu.jo)

R. A HajKhalil is with the Mechanical Engineering Department, Philadelphia University, Amman, Jordan (e-mail: ranahajkhalil@gmail. com). of their water. The next step was to select a cheap source of the energy that is required to evaporate water. Solar energy is an excellent one, since it is clean, cheap and available in abundance at the site. Fortunately, the Jordanian landscape is characterized by bright sunshine days almost throughout the year. Most of the country lies within the solar belt of the world, and marked by a dry climate and desert areas Solar distillation has been in practice for a long time.

A stepped basin is used to improve the performance of solar still by Kabeel et al. [1]. Two solar stills were used simultaneously. The influence of depth and width of trays on the performance of the stepped solar still was investigated. Feed water temperature to the stepped still was varied using a vacuum tube solar collector. For further augmentation of the yield a wick on the vertical sides is added to the stepped still. A good agreement between the experimental and theoretical results was observed. The results showed that the productivity of the stepped solar still strongly depends on the tray depth and width. Also it is found that maximum productivity of stepped still is achieved at a tray depth $5 \mathrm{~mm}$ and tray width $120 \mathrm{~mm}$, which is about $57.3 \%$ higher than that of the conventional still.

Arunkumar et al., [2] designed a solar still with a hemispherical top cover for water desalination with and without flowing water over the cover. The daily distillate output of the system was increased by lowering the temperature of the cover by water flowing over it. It was found that the efficiency of the still increased from $34 \%$ to $42 \%$ with the top cover cooling effect.

Tanaka [3] presented a basin type solar still with a flat plate external bottom reflector extending from the front wall of the still in addition to the internal. The authors proposed a geometrical model to calculate the direct solar radiation reflected by the external bottom reflector and then absorbed onto the basin liner. Further, they performed a numerical analysis of heat and mass transfer in the still. It was found that the external reflector can reflect the sunrays to the basin liner and increase distillate productivity. The daily amount of distillate of the still with internal and external bottom reflector is predicted to be $41 \%, 25 \%$ and $62 \%$ greater than that of a conventional basin type still on the spring equinox and summer and winter solstices, respectively, by setting the external reflector's inclination to the proper values according to the seasons when the glass cover's inclination angle is fixed at $20^{\circ}$ from horizontal and the length of the external reflector is the same as the length of the basin liner.

A modified photovoltaic thermal (PVT) double slope active solar still was designed and fabricated for remote Locations by Sing [4]. Photovoltaic operated DC water pump has been used between solar still and photovoltaic (PV) 
integrated flat plate collector to re-circulate the water through the collectors and transfer it to the solar still. It was found that the production rate has been accelerated to 1.4 times than the single slope hybrid (PVT) active solar still for the parallel configuration in forced mode in the month of October, 2010. The daily average energy efficiency of the solar still is obtained as $17.4 \%$. Comparative results have been predicted on annual basis with the single slope hybrid (PVT) active solar still accounting 250, 275 and 300 clear days in a year.

Feilizadeh et al., [5] developed a new radiation model for a single-slope solar still, which for the first time takes into account the effect of all walls of the still on the amount of incident solar radiation on the water surface and each wall. The predictions of the proposed model were compared with the experimental data, it was found that there is a good agreement between the theoretical results and the experimental data. Moreover, time variations of the incident beam radiation on different parts of a single-slope solar still are investigated. The results show that the effect of the back and side walls is not inconsiderable and they should be taken into consideration to improve the accuracy of the thermal radiation analysis of single-slope solar stills' performance.

Experimental Investigation to study the effect of coupling a flat plate solar collector on the productivity of solar stills was carried out by Badran and Al-Tahaineh [6]. Other different parameters (i.e. water depth, direction of still, solar radiation) to enhance the productivity were also studied. Single slope solar still with mirrors fixed to its interior sides was coupled with a flat plate collector. It was found that coupling of a solar collector with a still has increased the productivity by $36 \%$. Also the increase of water depth has decreased the productivity, while the still productivity is found to be proportional to the solar radiation intensity.

Al-Hinai et al., [7] reports the use of two mathematical models to compare the productivity of single-effect and double effect solar stills under different climatic, design and operational parameters in Oman. The shallow water basin, 23' cover tilt angle, 0 . $1 \mathrm{~m}$ insulation thickness, and asphalt coating of the solar still were found to be the optimum design parameters that produced an average annual solar still yield of $4.15 \mathrm{kgim} 2 / \mathrm{d}$ and $6 \mathrm{~kg} / \mathrm{mTd}$ for single and double effect solar stills, respectively. A cost analysis is carried out to shed some light on the potential of utilizing an array of single-effect solar stills or double-effect solar stills for the production of drinking water in remote areas in Oman. It has been found that the unit cost for distilled water using an array of single-effect solar stills is $\$ ` 74 / 1000$ gal $(16.3 \$ / \mathrm{m} 3)$ or $\$ 62.411000$ gal $(13.7 \$ / \mathrm{m} 3)$ when using a double-effect solar still. The cost saving is $15.7 \%$.

Solar stills required for any engineering application must be carefully selected based on the performance of these stills, such performance is found experimentally However, this is too difficult due to various measurement and heat transfer processes. In order to simplify this, computer codes are used for the estimation of the performance of systems. The algorithms employed are usually complicated, involving the solution of complex equations and such programs usually require large computer power and need a considerable long computational time

Instead artificial neural network (ANN) has been becoming increasingly popular in thermal engineering applications during the last decade. A number of studies have been introduced about using ANN in thermal applications [8]-[13].

The main objective of this study is to investigate the ability of ANN to estimate the performance of a triple basin solar still operating under Jordanian climate. The models to be used include nonlinear autoregressive exogenous model (NARX), Elman Network and Multilayer feedforward network.

\section{ARTIFICIAL NEURAL NETWORK (ANN)}

ANNs are computational models, which replicate the function of a biological network, composed of neurons and are used to solve complex functions in various applications [14]. In general, they are composed of three layers, which are an input layer, some hidden layers and an output layer [15]. The advantages of the ANNs are speed, simplicity and ability to train past data to provide the necessary predictions. ANN has been used in a wide range of applications such as recognition, optimization, clustering, regression and prediction.

To develop an ANN model, there is three steps must be followed. Firstly, the input is introduced with the desired output to the network together. Secondly, the network is trained to estimate the output in the training step. Finally, the testing step, in this step estimating output data are obtained by using the input data, which are not used in the training step. More details about these steps is found in [15].

The main objective of this study is to investigate the ability of ANN to estimate the performance of a triple basin solar still operating under Jordanian climate. The metrological data, which was obtained previously from experiments in [16], were used to train the neural network. Three layers network structure is shown in Fig. 1. Nine inputs variables (time, Hourly variation of cover glass temperature $\left(T_{g}\right)$, water temperature in the upper basin $\left(\mathrm{T}_{\mathrm{w} 1}\right)$, water temperature in the middle basin $\left(\mathrm{T}_{\mathrm{w} 2}\right)$ and water temperature in the lower basin of the triple basin still $\left(\mathrm{T}_{\mathrm{w} 3}\right)$, Distillate volume, ambient temperature $\left(\mathrm{T}_{\mathrm{a}}\right)$, plate temperature $\left(\mathrm{T}_{\mathrm{P}}\right)$ and hourly solar intensity $\left(I_{s}\right)$ ) are used in training three models of ANN network. One output variable is thermal efficiency $(\eta)$ of a triple basin solar still. The models to be used in the ANN include nonlinear autoregressive exogenous model (NARX), Elman and feedforward network. A brief introduction to the three neural network models to be used in this study is found in [17].

The aim of the below ANN is to estimate the efficiency of the triple basin solar collector by using previously obtained experimental data in [16]. Three types of ANN is constructed and tested by using MATLAB neural network module to solve this problem and to test the ability of each ANN to estimate $\eta$. The performance of the proposed model has been carried out using three global statistics: coefficient of determination $\left(\mathrm{R}^{2}\right)$, root mean squared error (RMSE) and mean bias error (MBE). More details about these parameters 
is found in [15]. These three parameters are given by:

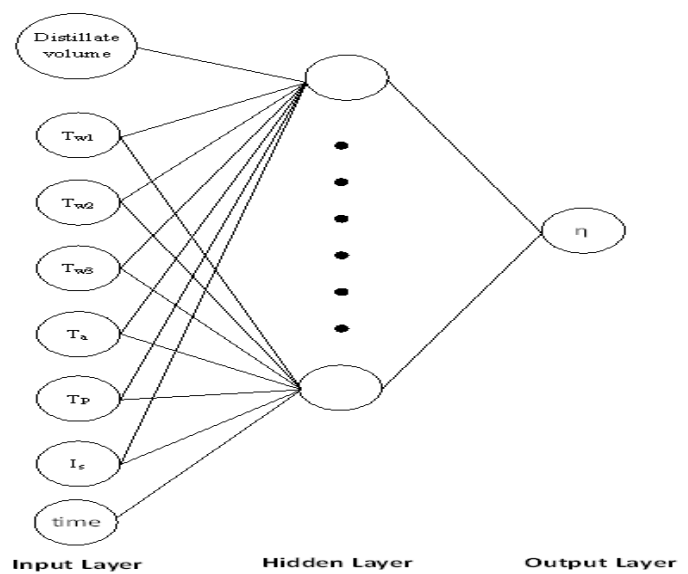

Fig. 1. The architecture of ANN used for this study.

$$
\begin{gathered}
R^{2}=1-\frac{\sum_{j}\left(t_{j}-o_{j}\right)^{2}}{\sum_{j}\left(o_{j}\right)^{2}} \\
R M S E=\sqrt{\frac{\sum_{j}\left(t_{j}-o_{j}\right)^{2}}{p}} \\
M B E=\frac{\sum_{j}\left(t_{j}-o_{j}\right)}{p}
\end{gathered}
$$

where:

$t_{j}$ is the target value,

$o_{j}$ is the output value and

$p$ is the pattern

Three types of ANN network with neuron numbers $(9,10$, 1) was constructed and tested by MATLAB software. Total data consists of 46 samples were obtained from previously experimental data is used as the input of ANN network. Totally, $40 \%$ of this data is used for training, $30 \%$ is used for validation and $30 \%$ is used for testing. In network, it was used Scaled Conjugate Gradient (trainscg) algorithm function. The number of the hidden layer was selected as 10 in this study after many trails and errors. Tangent sigmoid function was applied for the hidden layer, and linear transfer function is used in the output layer.

\begin{tabular}{lc}
\multicolumn{2}{c}{ TABLE I: TRAINING PARAMETERS } \\
\hline \hline $\mathrm{e}$ & 1 \\
\hline Epochs between displays & 500 \\
Maximum number of epochs to train & inf \\
Maximum time to train in seconds & 0 \\
Performance goal & 6 \\
Maximum validation failures & 1 \\
Factor to use for memory/ speed & $1 * 10^{-6}$ \\
Tradeoff & \\
Minimum gradient error
\end{tabular}

\section{Discussion OF RESUltS}

Three Artificial Neural Network models (Feedforward, Elman, and Nonlinear Autoregressive Exogenous (NARX) networks) were used to find the performance of triple basin solar still operating under Jordanian climate.

\section{A. NARX Network}

In the NARX network, the training was stopped after 25 epochs with trainscg function. The Root Mean Square Error (RMSE) of training period was 0.7973, and RMSE of validation period was 0.7331 .

Variation of the gradient error and validation checks at each epoch are shown in fig. 2 , as indicated in this figure, the gradient error is 8.3437 and the number of validation checks are 6 at 25 epochs.

Scatter plot of training, validation, testing of experimental data are shown in fig. 3 , as it may be noticed in this figure, it was found that the values of $\mathrm{R}$ in training period, validation period, and testing period are $0.99856,0.99952$ and 0.9971 respectively. The maximum performance was found to be 0.53742 at epoch number 19 .

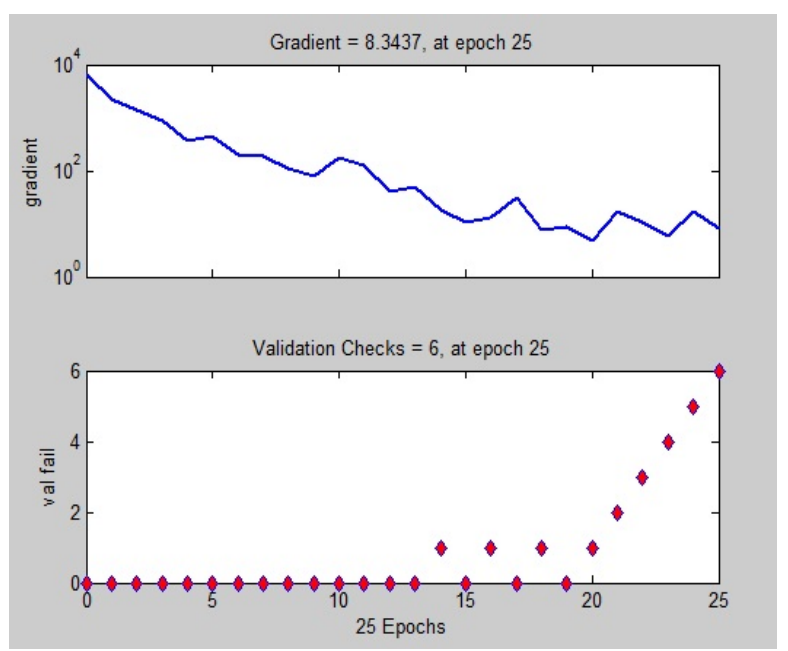

Fig. 2. The variation of gradient error and validation checks NARX Network.
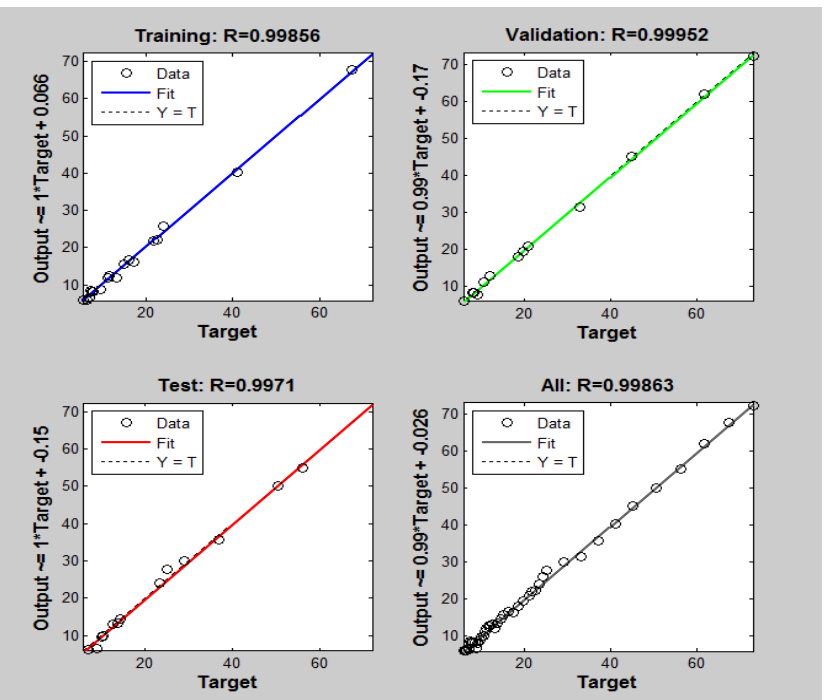

Fig. 3. Scatter plot of training, validation, test and all data to NARX Network.

\section{B. Elman Network}

In Elman network, the training was stopped after 8 epochs 
with trainscg function. The RMSE of training period was found to be 10.3158 , and RMSE of validation period was found to be 6.2029 .

Variation of the gradient error and validation checks at each epoch are shown in Fig. 4, as indicated in this figure, the gradient error is 246.1863 , and the number of validation checks are 6 at 8 epochs.

Scatter plot of training, validation, testing of experimental data are shown in Fig. 5, as it may be noticed in this figure, it was found that the values of $\mathrm{R}$ in training period, validation period, and testing period are $0.92214,0.95922$ and 0.7917 respectively. The maximum performance was found to be at epoch number.

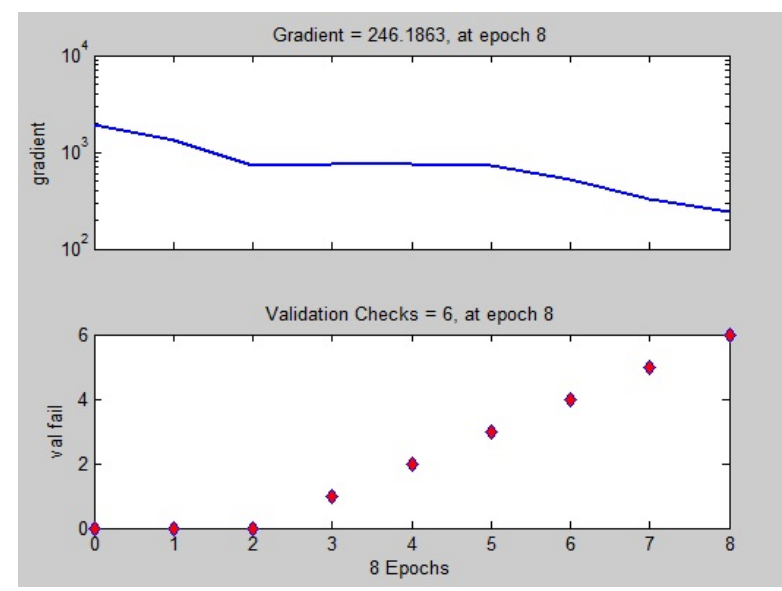

Fig. 4. The variation of gradient error and validation checks to Elman Network.
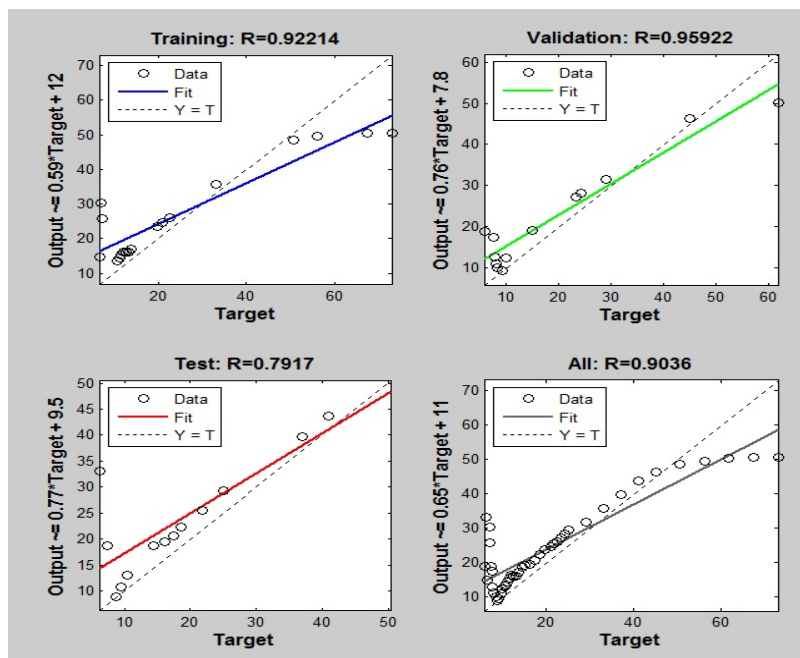

Fig. 5. Scatter plot of training, validation, test and all data to Elman Network.

\section{Feedforward Network}

In the Feedforward network, the training was stopped after 35 epochs with trainscg function. The RMSE of training period was found to be, and RMSE of validation period was found to be.

Variation of the gradient error, and validation checks at each epoch are shown in Fig. 6, as indicated in this figure, the gradient error is 8.2002, and the number of validation checks are 6 at 35 epochs.

Scatter plot of training, validation, testing of experimental data are shown in Fig.7, as it may be noticed in this figure, it was found that the values of $\mathrm{R}$ in training period, validation period, and testing period are $0.99953,0.99873$ and 0.99838 respectively. The maximum performance was found to be 0.96538 at 29 epoch number.

The comparison between the obtained experimental data and the estimated efficiency for the three ANN networks are shown in Fig. 8.

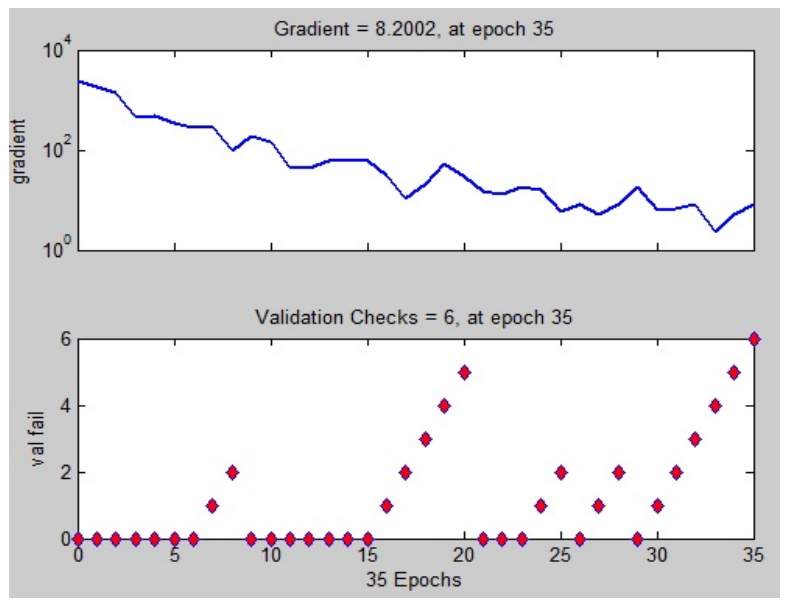

Fig. 6. The variation of gradient error and validation checks to Feedforward Network.
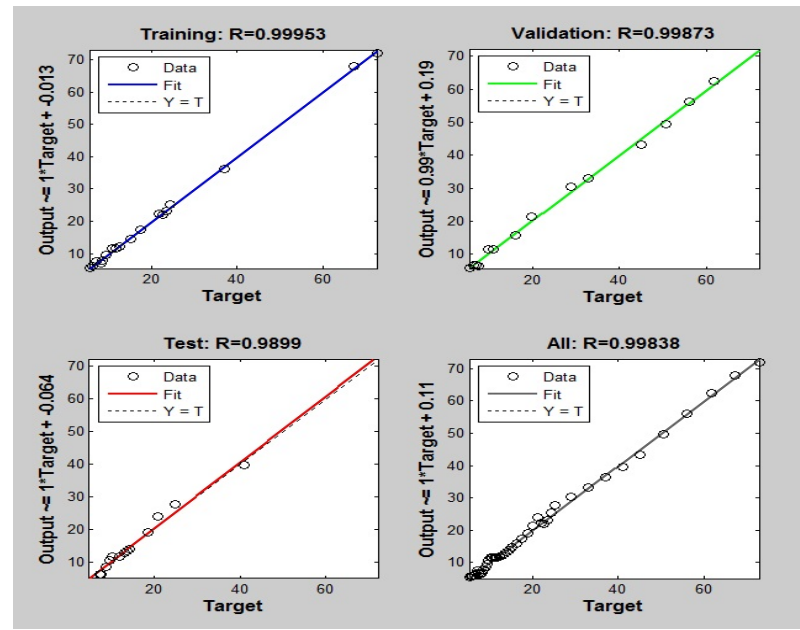

Fig. 7. Scatter plot of training, validation, test and all data to Feedforward Network.

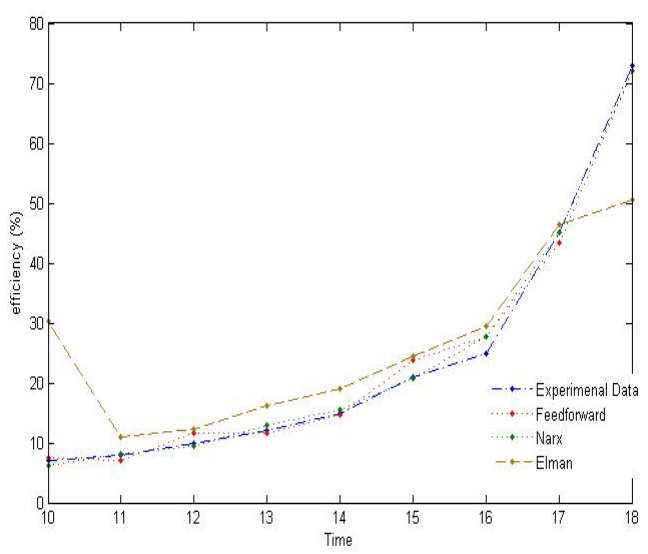

Fig. 8. Comparison between experimental and estimated thermal efficiency.

From the table and figures for the three ANN model, it may be noticed that Feedforward is characterized by more accurate results compared with those of Elman network and NARX network. Consequently, this model may be used to estimate the data with a high accuracy. 
TABLE II: COMPARISON OF PERFORMANCE OF THE USED MODELS.

\begin{tabular}{ccccccc}
\hline & \multicolumn{2}{c}{ RMSE } & \multicolumn{2}{c}{ MBE } & \multicolumn{2}{c}{ R } \\
& Training & Validation & Training & Validation & Training & Validation \\
Elman & 10.3158 & 6.2029 & 7.4950 & 4.7990 & 0.92214 & 0.95922 \\
Feedforward & 0.5954 & 0.9825 & 0.5133 & 0.7714 & 0.99953 & 0.99873 \\
NARX & 0.7973 & 0.7331 & 0.6900 & 0.5518 & 0.99856 & 0.99952 \\
\hline
\end{tabular}

\section{CONCLUSION}

In this study, artificial neural network models using trainscg learning algorithm was successfully used to estimate the relation between the efficiency of triple basin solar still and the inputs variables of solar still. ANN technique was used with three different models (feedforward network, Elman, and NARX).

The comparisons between the estimated data and experimental data showed that ANN models have ability to recognize the relationship between inputs and output variables. Also the statistical error analysis showed the accuracy of ANN models.

On the other hand, the obtained results indicate that NARX model and Elman model have the least ability for the estimation of the thermal efficiency of the solar collector while Feedforward has the best performance.

\section{REFERENCES}

[1] A. E. Kabeel, A. Khalil, Z. M. Omara, and M. M. Younes, "Theoretical and experimental parametric study of modified stepped solar still," Desalination, vol. 289, pp. 12-20, 2012.

[2] T. Arunkumar, R. Jayaprakash, D. Denkenberger, et al., "An experimental study on a hemispherical solar still," Desalination, vol. 286, pp. 342-348, 2011.

[3] Hiroshi Tanaka, "A theoretical analysis of basin type solar still with flat plate external bottom reflector," Desalination, vol. 279, Issues 1-3, pp. 243-251, 2011.

[4] Gajendra Singh, Shiv Kumar, and G. N. Tiwari, "Design, fabrication and performance evaluation of a hybrid photovoltaic thermal (PVT) double slope active solar still," Desalination, vol. 277, Issues 1-3, no. 15, pp. 399-406, 2011.

[5] M. Feilizadeh, M. Soltanieh, K. Jafarpur, and M. R. K. Estahbanati, “A new radiation model for a single-slope solar still," Desalination, vol. 262, Issues 1-3, pp. 166-173, 2010.

[6] O. O. Badran and H. A. Al-Tahaineh, "The effect of coupling a flat-plate collector on the solar still productivity," Desalination, vol. 183, pp. 137-142, 2005.

[7] H. Al-Hinai, MS. Al-Nassri, and B. A. Jubran, "Parametric investigation of a double-e eGt solar still in comparison with a single-effect solar still," Desalination, vol. 150, pp. 75-83, 2002.

[8] H. M.Ertunc and M. Hosoz, "Artificial neural network analysis of a refrigeration system with an evaporative condenser," Applied Thermal Engineering, vol. 26, pp. 627-635, 2006.

[9] S. A. Kalogirou, "Artificial neural networks in renewable energy systems applications: a review," Renewable and Sustainable Energy Reviews, vol. 5, pp. 373-401, 2001

[10] S. A. Kalogirou, "Prediction of flat-plate collector performance parameters using artificial neural networks," Solar Energy, vol. 80, pp. 248-259, 2006.

[11] A. Mellita and S. A. Kalogirou, "Artificial intelligence techniques for photovoltaic applications: A review," Progress in Energy and Combustion Science, vol. 34, pp. 574-632, 2008.

[12] A. Sozen, E. Arcaklioglu, and M. Ozkaymak, "Turkey's net energy consumption," Applied Energy, vol. 81, pp. 209-221, 2005.
[13] I. H. Yang, M. S. Yeo, and K.W. Kim, “Application of artificial neural network to predict the optimal start time for heating system in building," Energy Conversion and Management, vol. 44, pp. 2791-2809, 2003.

[14] A. Sozen, T. Menlik, and S. Unvar, "Determination of efficiency of flat-plate solar collectors using neural network approach," Expert Systems with Applications, vol. 35, pp. 1533-1539, 2008.

[15] M. Caner, E. Gedik, and A. Keçebas, "Investigation on thermal performance calculation of two type solar air collectors using artificial neural network," Expert Systems with Applications, vol. 38, pp. 1668-167, 2011 .

[16] M. A. Hamdan, A. M. Musa, and B. A. Jubran, "Performance of solar still under Jordanian climate," Energy Conversion and Management, vol. 40, pp. 495-503, 1999.

[17] A. Moghaddamnia, R. Remesan, M. H. Kashani, M. Mohammadi, D. Han, and J. Piri, "Comparison of LLR, MLP, Elman, NNARX and ANFIS Models - with a case study in solar radiation estimation," Journal of Atmospheric and Solar-Terrestrial Physics, vol. 71, pp. 975-982, 2009.

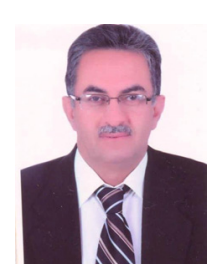

Mohammad A. Hamdan received his Ph.D. in Mechanical Engineering from Washington State University (Pullman) (USA), M.Sc. in Mechanical Engineering (Combustion \& Energy) from the University of Leeds, United Kingdom and B.Sc. in Mechanical Engineering from the University of Wales (Cardiff), United Kingdom. He is a full professor since 1995 and he worked as Engineering sector Advisor at Higher council for science and technology. He was dean of engineering at the University of Jordan (1997-2001), and dean of engineering at Hashemite University (2001-2003). He is currently on a leave without pay at Al-Zaytoonah University, Amman Jordan acting as the dean of Faculty of Engineering. he published over one hundred papers in international journals and his research experience is alternative fuels, combustion and pollution, heat transfer and renewable energy.

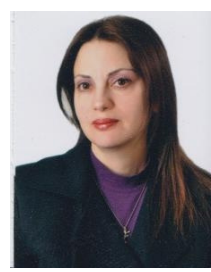

Rana HajKhalil received her Ph.D. in Mechanical Engineering from University of Jordan, (Amman, Jordan), M.Sc. in Mechanical Engineering (Solar Energy) from the University of Jordan, Jordan and B.Sc. in Mechanical Engineering from the University of Kuwait, (Kuwait). She is assistant professor since 2009 at the Mechanical Engineering Department, Philadelphia University. Jerash, Jordan.

She worked as a Lecturer at the Mechanical Engineering Department, Philadelphia University. Jerash, Jordan (2002-2009).

She worked as Scientific Assistant at the Mechanical Engineering Department, Applied Science University from (1995-2000). Amman, Jordan. She worked as a mechanical engineer from (1992-1995)

She published three papers in international journals and his research experience is alternative fuels, combustion and pollution and renewable energy.

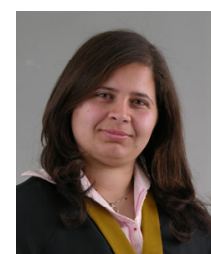

Eman A. Abdelhafez received her M.Sc. degree in Mechanical engineering from the University of Jordan and B.Sc. in Mecahtronics engineering from the University of Jordan. She is currently lecturer since 2009 at Alzaytoonah University of Jordan. Currently she is the Director of Quality assurance office at the engineering Faculty since 2011. Her research interest are microelectromechanical systems (MEMS), Microfluid, Engineering Application in Artificial Intelligent and energy. 